\title{
Interactions of polar hydrogen bond donor solvents with ions: a theoretical study
}

\author{
Jan S. Jaworski ${ }^{1}$ Barbara Bankiewicz ${ }^{2}$ T. Marek Krygowski ${ }^{1} \cdot$ Marcin Palusiak $^{3}$. \\ Olga A. Stasyuk ${ }^{4} \cdot$ Halina Szatylowicz ${ }^{4}$
}

Received: 3 March 2016/Accepted: 6 May 2016/Published online: 7 June 2016

(c) The Author(s) 2016. This article is published with open access at Springerlink.com

\begin{abstract}
Intermolecular interactions between molecules of protic solvents (water, methanol, formic acid, formamide, methylamine and ammonia) and monatomic ions $\left(\mathrm{Li}^{+}, \mathrm{Na}^{+}, \mathrm{K}^{+}, \mathrm{F}^{-}, \mathrm{Cl}^{-}\right.$and $\left.\mathrm{Br}^{-}\right)$were characterized by the total energy of interaction $\left(E_{\text {total }}\right)$ and the amount of charge which is transferred between the solvent molecule and the ion $(\mathrm{CT})$. For the studied systems, linear relationships between $E_{\text {total }}$ and $\ln (\mathrm{CT})$ were observed and explained. In the case of complexes with metal cations, a good linear correlation between $E_{\text {total }}$ and the molar enthalpy of ion solvation $\left(\Delta H_{\mathrm{i}, \text { solv }}^{\mathrm{o}}\right)$, obtained from experimental data for water, methanol, formamide and ammonia, was found. On the other hand, for complexes with anions, a planar regression between $E_{\text {total }}$ and two explanatory parameters: $\Delta H_{\mathrm{i}, \text { olv }}^{\mathrm{o}}$ and $\Delta H_{\mathrm{vap}}$ (molar heat of vaporization for a given
\end{abstract}

Dedicated to Professor Jerzy Blazejowski on the occasion of his 70th birthday anniversary.

Electronic supplementary material The online version of this article (doi:10.1007/s11224-016-0769-y) contains supplementary material, which is available to authorized users.

Jan S. Jaworski

jaworski@chem.uw.edu.pl

$\bowtie$ Barbara Bankiewicz

b.bankiewicz@uwb.edu.pl

1 Faculty of Chemistry, University of Warsaw, Pasteura 1, 02-093 Warsaw, Poland

2 Institute of Chemistry, University of Bialystok, Ciolkowskiego 1K, 15-245 Bialystok, Poland

3 Faculty of Chemistry, University of Lodz, Pomorska 163/165, 90-236 Lodz, Poland

4 Faculty of Chemistry, Warsaw University of Technology, Noakowskiego 3, 00-664 Warsaw, Poland solvent), was established. The latter shows an important role played by solvent-solvent interactions around anions, which is in agreement with some literature predictions based on the mean spherical approximation.

Keywords Hydrogen bond donor (HBD) solvents - Lewis acidity/basicity · Quantum chemistry modeling · Solvation energy

\section{Introduction}

Chemical and physicochemical properties of chemical species in solutions depend in a dramatic way upon the nature of the solvent applied. A good example was presented in the preface to the second edition of the famous Hammett monograph [1], namely that some reactions undergoing in the presence of bases are faster in dimethyl sulfoxide than in methanol by a factor of $10^{13}$ ! This situation is due to various (not always fully recognized) kinds of interactions between the molecules of a solvent, which sometimes are reagents, and solutes. There are several kinds of interactions between solute and solvent molecules which should be taken into account: first of all, physical interactions, where the solvent is considered as a continuum medium characterized by its relative permittivity and/or refractive index [2-4]. Another approach to this problem is based on accounting for purely electrostatic interactions by means of charge-charge, charge-dipole and dipole-dipole interactions [5a], which also depend on the solvent's relative permittivity and/or refractive index [6]. There is also a thermodynamic approach based on the Hildebrand solubility parameter $\delta$, applicable for estimating the solubility of nonelectrolytes in organic solvents [7]. Finally, chemical approaches considering solute-solvent interactions in terms of Lewis acidity/basicity 
[8-13], electron pair donors/acceptors [14, 15] and H-bonding donors/acceptors [16, 17] should be distinguished there. In some cases, solvent effects on chemical and physicochemical properties were described by mixing physical and chemical approaches $[6,18]$. All these problems are widely presented and thoroughly discussed in an excellent monograph by Reichardt and Welton [5]. The results obtained by different chemical approaches, based on various physicochemical solute processes, are quite often correlated [12, 13, 15, 19, 20]. However, a problem arises when numerical values of a given scale are considered in detail and examined in particular cases. Usually, solvent parameters are estimated by some reference reaction (or process), and neither acidity nor basicity is measured in an isolated way. Thus, even after normalization, usually in the range of $0-1$, acidity and basicity of a given solvent have only relative character. The sensitivity of a given scale is different in various ranges of this scale. Moreover, each solvent molecule is characterized by both of these functions. For example, the hydroxy group of methanol has the acidity function, Reichardts normalized $E_{T}^{N}$ value is equal to 0.76 [5b], whereas its basicity function expressed by the KamletTaft parameter $\beta$ is equal to 0.66 [5c]. Another disadvantage of empirical scales of Lewis acid/base properties of a solvent may be exemplified by too weak interactions that intervene between the active part of the probed molecule and solvent molecules which can form clusters that are strong enough to make the interactions not effective. A good example of such an effect is the low value of the basicity parameter $\beta$ for water, which is equal to 0.14 , whereas for methanol, it is equal to 0.62 [16]. This discrepancy may be easily explained. The NH hydrogen atoms in the probed molecule-4-nitroaniline-are too weakly acidic to destroy the cluster structure of liquid water in which the concentration of free water molecules is too small to affect the $n \rightarrow \pi$ band in its $\mathrm{UV} / \mathrm{Vis}$ spectrum, which are the experimental way for estimation of the $\beta$ values [21].

In many cases, molecules may interact with ions which can serve either as Lewis acids (cations) or as bases (anions). Moreover, some reactions/processes are accompanied by the presence of ionic or strongly dipolar intermediates. Therefore, the sensitivity of solvent molecules to interactions with ions may play an important role. To study these kinds of problems, we selected six molecules which represent solvents with three most important functional groups: hydroxy, amino and carboxyl; see Schemes 1 and 2. All these solvents belong to a group of hydrogen-bond donor (HBD) solvents with molecules associated by hydrogen bonds. Thus, the main contribution to the solvation of the simple ions considered can be the interactions of cations with the loneelectron pairs of donor oxygen or nitrogen atoms of solvent molecules and the hydrogen bonding with anions.
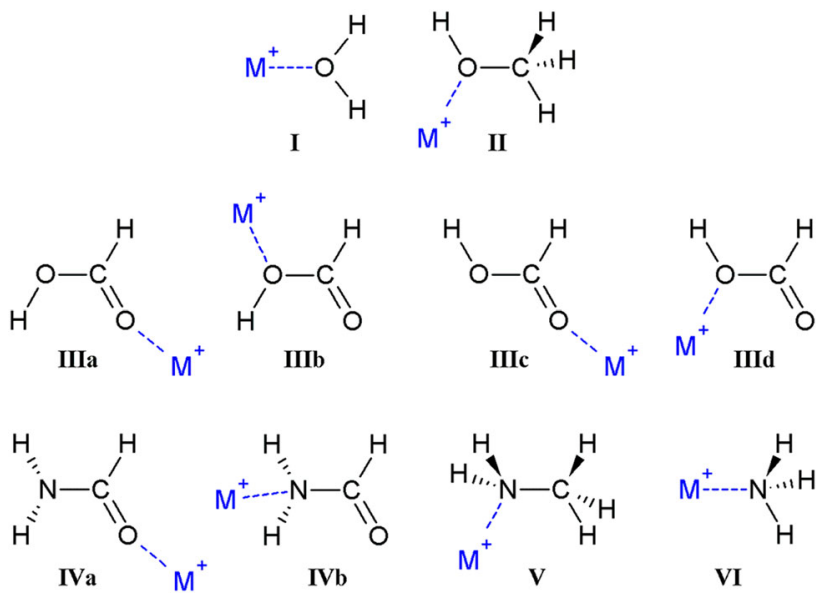

Scheme 1 Schematic presentation of the analyzed complexes of cations $\left(\mathrm{M}^{+}=\mathrm{Li}^{+}, \mathrm{Na}^{+}, \mathrm{K}^{+}\right)$with water, methanol, formic acid, formamide, methylamine and ammonia
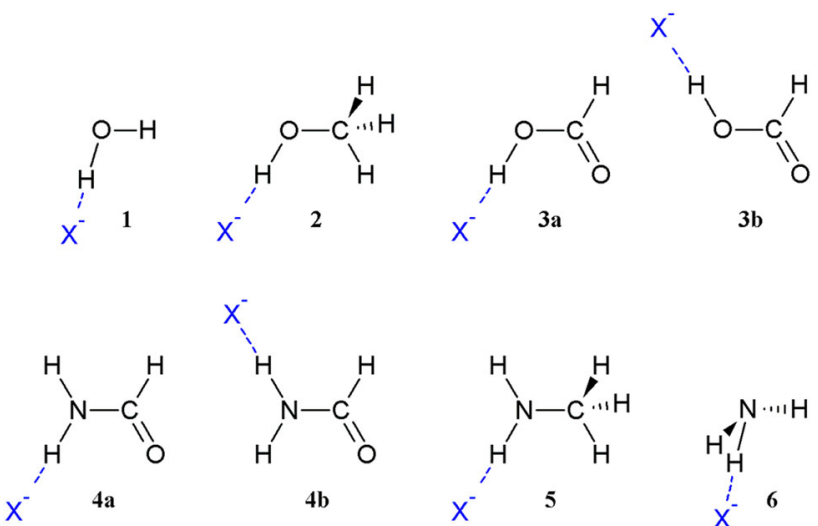

Scheme 2 Schematic presentation of the analyzed complexes of anions $\left(\mathrm{X}^{-}=\mathrm{F}^{-}, \mathrm{Cl}^{-}, \mathrm{Br}^{-}\right)$with water, methanol, formic acid, formamide, methylamine and ammonia

The aim of this paper is to identify in a quantitative and absolute way (without any reference systems) the Lewis basicity or acidity of particular active centers of solvent molecules mentioned above and also to compare the energies of their interactions with cations/anions with experimental quantities of individual ions.

\section{Methodology}

All calculations presented in this work were carried out with the Gaussian 09 suite of programs [22]. The geometries of the $\mathrm{A} \cdots \mathrm{B}$ complexes (equilibrium and nonequilibrium) and the respective monomers (molecules of solvents, cations and anions) were optimized with the DFT method using the Becke-style hybrid functional with Lee-YangParr gradient correction, B3LYP [23, 24], and the 
6-311++G(d,p) basis set. The non-equilibrium geometries were constructed in the following way. The distances in considered intermolecular interacting ion/solvent molecule and the related bond angle (only in the case of complexes with anions) were fixed on arbitrary values $(50,100$ and $150 \mathrm{pm}$, and $180^{\circ}$, respectively). The rest of the geometrical parameters were optimized.

This procedure allows to simulate the influence of the increase in distance between a given ion/solvent molecule pair on selected parameters of the investigated complex.

The ability of the B3LYP/6-311++G(d,p) computational level to characterize the investigated systems was checked by calculating the gas-phase lithium cation basicity (LCB) and lithium cation affinity (LCA); for details, see supporting information (SI). The obtained values of LCA and LCB as well as experimental data [2529] are presented in Table S1 (SI). The calculated values of LCA and LCB are always larger than the experimental ones; however, taking into account the experimental error, they are compatible with each other. Therefore, it was found that B3LYP adequately (but with some systematic error) describes the lithium cation binding energies.

General schemes of the analyzed complexes of solvent molecules with cations and anions are shown in Schemes 1 and 2 , respectively.

The geometries of the equilibrium $\mathrm{A} \cdots \mathrm{B}$ complexes were confirmed to be true minima using the frequency analysis. Imaginary frequencies (corresponding to motions along fixed geometrical parameters) were found only for complexes in non-equilibrium geometries.

The total energy of interaction (the binding energy) for the analyzed A $\cdots$ B complexes, $E_{\text {total }}$, was calculated as the difference between the energy of the complex and the sum of the energies of its components (for geometries obtained during the optimization procedure of the complex and monomers, respectively). The counterpoise procedure of the Boys and Bernardi [30] was used to correct the interaction energy by basis set superposition error.

The quantum theory of atoms in molecules (QTAIM) was applied to analyze the properties of intermolecular interactions in A $\cdots \mathrm{B}$ complexes. QTAIM calculations were performed with AIMAll software package [31] using the B3LYP/6-311++G(d,p) wave functions as input. In that context, it is worth mentioning that the charge transfer estimated as a charge flow between closed-shell molecular fragments is not dependent on the population analysis scheme, even if partial charges located on individual atoms can differ significantly depending on the scheme used for space partitioning [32]. Statistical analysis was performed using a computer program of Dr W. Hyk available at www. e-stat.pl.

\section{Results and discussion}

Interactions between solvent and solute molecules have long been considered in terms of Lewis acidity-Lewis basicity. This kind of solvent properties is usually quantified using the appropriate solvent parameters (for review, see Refs. [5, 6]). From the viewpoint of a quantum chemical approach, the Lewis acidity/basicity of a solvent can be characterized by its binding energy with the ion (anion/cation). If ions belong to hard Lewis acids or bases, the nature of their interactions with solvent is mostly electrostatic and is often associated with some kind of charge transfer between the interacting ion and the molecule in question. Therefore, such interactions can also be characterized by the magnitude of the transferred charge $\mathrm{CT}$. The above-mentioned characteristics are presented and discussed in two following parts dealing separately with cations and anions, whereas a comparison of the obtained characteristics of the intermolecular interactions with available experimental parameters is presented in the last part of this section.

\section{Interactions with cations}

Three hard or nonpolarizable cations [33, 34] were selected: $\mathrm{Li}^{+}, \mathrm{Na}^{+}$and $\mathrm{K}^{+}$(in order of slightly decreasing hardness), because "pure" electrostatic interactions can be expected between hard Lewis acids and hard Lewis bases.

Table 1 contains data for the most important equilibrium complexes, whereas Tables S2-S4 (SI) present also the data for modeled complexes in which cations were gradually moved away by 50,100 and $150 \mathrm{pm}$ from the equilibrium position. All tables contain the distance between an ion and a proper atom in a solvent molecule, $d_{\mathrm{O} / \mathrm{N} \cdots \mathrm{M}}{ }^{+}$(or $d_{\mathrm{H} \cdots \mathrm{X}}{ }^{-}$in the case of anions), the total energy of interactions, $E_{\text {total }}$, the amount of CT and the ratio of potential, $V$ and kinetic electron energy density, $G$, at bond critical point (BCP) for intermolecular interactions, $\mid V_{\mathrm{BCP}} / / G_{\mathrm{BCP}}$ [35], which characterizes the nature of interactions. An increasing value of this ratio indicates a more covalent character of the bond.

Figure 1 shows the dependences of the total energy of interactions, $E_{\text {total }}$, on the magnitude of CT during interaction of cations with the oxygen (Fig. 1a) and nitrogen (Fig. 1b) atoms of solvents including the data for nonequilibrium complexes. The obtained data for formamide (IVa, IVb) and formic acid (IIIb, IIId) are outliers since in these cases, the binding energy is affected by a resonance effect due to $n-\pi$ conjugation $\mathrm{HY}-$ $\mathrm{CH}=\mathrm{X} \leftrightarrow{ }^{+} \mathrm{HY}=\mathrm{CH}-\mathrm{X}^{-}(\mathrm{X}=\mathrm{O}, \mathrm{Y}=\mathrm{NH}, \mathrm{O})[32$, 36]. 
Table 1 Selected parameters of $\mathrm{O} / \mathrm{N} \cdots \mathrm{M}^{+}$interactions of solvents molecules with cations $\mathrm{M}^{+}=\mathrm{Li}^{+}, \mathrm{Na}^{+}, \mathrm{K}^{+}$in equilibrium complexes

\begin{tabular}{|c|c|c|c|c|c|}
\hline Complex & Interaction & $d_{\mathrm{O} / \mathrm{N} \cdots \mathrm{M}}{ }^{+}(\mathrm{pm})$ & $E_{\text {total }}\left(\mathrm{kJ} \mathrm{mol}^{-1}\right)$ & $\left|V_{\mathrm{BCP}}\right| / G_{\mathrm{BCP}}$ & CT (a.u.) \\
\hline \multirow[t]{3}{*}{ I } & $\mathrm{O} \cdots \mathrm{Li}^{+}$ & 184.1 & -149.0 & 0.775 & 0.036 \\
\hline & $\mathrm{O} \cdots \mathrm{Na}^{+}$ & 222.5 & -104.2 & 0.782 & 0.031 \\
\hline & $\mathrm{O} \cdots \mathrm{K}^{+}$ & 261.8 & -76.8 & 0.820 & 0.025 \\
\hline \multirow[t]{3}{*}{ II } & $\mathrm{O} \cdots \mathrm{Li}^{+}$ & 181.8 & -163.2 & 0.789 & 0.041 \\
\hline & $\mathrm{O} \cdots \mathrm{Na}^{+}$ & 220.6 & -112.0 & 0.793 & 0.035 \\
\hline & $\mathrm{O} \cdots \mathrm{K}^{+}$ & 259.0 & -81.3 & 0.835 & 0.029 \\
\hline \multirow[t]{3}{*}{ IIIa } & $\mathrm{O} \cdots \mathrm{Li}^{+}$ & 177.6 & -163.6 & 0.773 & 0.040 \\
\hline & $\mathrm{O} \cdots \mathrm{Na}^{+}$ & 215.9 & -112.5 & 0.774 & 0.032 \\
\hline & $\mathrm{O} \cdots \mathrm{K}^{+}$ & 254.5 & -81.4 & 0.800 & 0.027 \\
\hline \multirow[t]{3}{*}{ IIIb } & $\mathrm{O} \cdots \mathrm{Li}^{+}$ & 187.9 & -90.2 & 0.778 & 0.036 \\
\hline & $\mathrm{O} \cdots \mathrm{Na}^{+}$ & 228.4 & -52.1 & 0.787 & 0.031 \\
\hline & $\mathrm{O} \cdots \mathrm{K}^{+}$ & 272.8 & -29.3 & 0.818 & 0.021 \\
\hline \multirow[t]{3}{*}{ IIIc } & $\mathrm{O} \cdots \mathrm{Li}^{+}$ & 177.2 & -162.9 & 0.771 & 0.040 \\
\hline & $\mathrm{O} \cdots \mathrm{Na}^{+}$ & 215.4 & -111.2 & 0.772 & 0.032 \\
\hline & $\mathrm{O} \cdots \mathrm{K}^{+}$ & 253.4 & -79.3 & 0.799 & 0.027 \\
\hline \multirow[t]{3}{*}{ IIId } & $\mathrm{O} \cdots \mathrm{Li}^{+}$ & 188.5 & -99.1 & 0.773 & 0.035 \\
\hline & $\mathrm{O} \cdots \mathrm{Na}^{+}$ & 227.4 & -62.2 & 0.782 & 0.031 \\
\hline & $\mathrm{O} \cdots \mathrm{K}^{+}$ & 269.9 & -38.6 & 0.815 & 0.022 \\
\hline \multirow[t]{3}{*}{ IVa } & $\mathrm{O} \cdots \mathrm{Li}^{+}$ & 173.7 & -215.7 & 0.785 & 0.046 \\
\hline & $\mathrm{O} \cdots \mathrm{Na}^{+}$ & 211.7 & -154.1 & 0.782 & 0.036 \\
\hline & $\mathrm{O} \cdots \mathrm{K}^{+}$ & 248.1 & -117.5 & 0.814 & 0.034 \\
\hline \multirow[t]{3}{*}{$\mathrm{IVb}$} & $\mathrm{N} \cdots \mathrm{Li}^{+}$ & 202.9 & -87.2 & 0.839 & 0.042 \\
\hline & $\mathrm{N} \cdots \mathrm{Na}^{+}$ & 244.4 & -48.2 & 0.818 & 0.045 \\
\hline & $\mathrm{N} \cdots \mathrm{K}^{+}$ & 292.7 & -23.4 & 0.840 & 0.031 \\
\hline \multirow[t]{3}{*}{ V } & $\mathrm{N} \cdots \mathrm{Li}^{+}$ & 196.3 & -176.5 & 0.860 & 0.049 \\
\hline & $\mathrm{N} \cdots \mathrm{Na}^{+}$ & 235.2 & -121.9 & 0.835 & 0.059 \\
\hline & $\mathrm{N} \cdots \mathrm{K}^{+}$ & 277.0 & -83.9 & 0.874 & 0.045 \\
\hline \multirow[t]{3}{*}{ VI } & $\mathrm{N} \cdots \mathrm{Li}^{+}$ & 197.1 & -169.9 & 0.846 & 0.046 \\
\hline & $\mathrm{N} \cdots \mathrm{Na}^{+}$ & 235.5 & -118.7 & 0.824 & 0.053 \\
\hline & $\mathrm{N} \cdots \mathrm{K}^{+}$ & 278.0 & -83.0 & 0.858 & 0.041 \\
\hline
\end{tabular}

To the best of our knowledge, the relationships between interaction energy and CT shown in Fig. 1 were not discussed for solvent-solute interactions. In our opinion, they may have a simple chemical interpretation. The binding energy, $E_{\text {total }}$, describes approximately the enthalpy of solvation of a given ion because the entropy term was not taken into account in the calculations. Such an interpretation of the $E_{\text {total }}$ will be supported in "Interrelation between $E_{\text {total }}$ and enthalpies of ion solvation" section by a comparison with experimental enthalpies of ion solvation, $\Delta H_{\mathrm{i}, \text { solv }}^{\mathrm{o}}$. On the other hand, the magnitude of CT describes the competition between the cation and the oxygen or nitrogen atoms of the solvent molecule to attract a negative charge. That competition leads finally to an equilibrium state with the minimal energy, and hence, the CT parameter may resemble the reaction quotient changing its value toward the equilibrium constant. The situation is similar to the dissociation of a Brønsted acid in aqueous solution: the competitive interactions of the $\mathrm{H}^{+}$ion with the water molecule and with an anion of the acid (conjugate base) results in stronger dissociation (and a higher equilibrium constant) if attraction by the water molecule is more effective than that by an anion. Accepting this assumption, we can expect a simple relation between $E_{\text {total }}$ and $\ln (\mathrm{CT})$. As a consequence of the proposed interpretation, the slopes of regression lines shown in Fig. 1 should depend on the cation ability to electrostatic interactions which, for monovalent ions, depend mainly on their radii. Indeed, the slopes observed change in the order $\mathrm{Li}^{+}, \mathrm{Na}^{+}, \mathrm{K}^{+}$as shown by the plots in Fig. 1. Detailed statistical data for all plots in the case of cations are presented in Table 2. They will be discussed quantitatively in "Interactions with anions" section in comparison with the results obtained for anions.

The nature of the intermolecular interactions of solvents with cations was characterized by the QTAIM method. In 
all complexes studied only positive values of the Laplacian of electron density at BCP were found. This means that the electron charge has a depletion within the region between interacting atoms, indicating that both interactions are of a closed-shell type [35]. Additionally, the ratio $\left|V_{\mathrm{BCP}}\right|$ $G_{\mathrm{BCP}}<1$ indicates a pure closed-shell type of interactions. Therefore, it can be suggested that interactions with metal cations are of predominantly electrostatic nature. The value of $\left|V_{\mathrm{BCP}}\right| / G_{\mathrm{BCP}}$ ratio increases with an increase in the ionic radii, i.e., with a decrease in cation hardness. This agrees with the concept that interactions formed by hard Lewis acids are less covalent in nature than those with participation of soft ones [33].
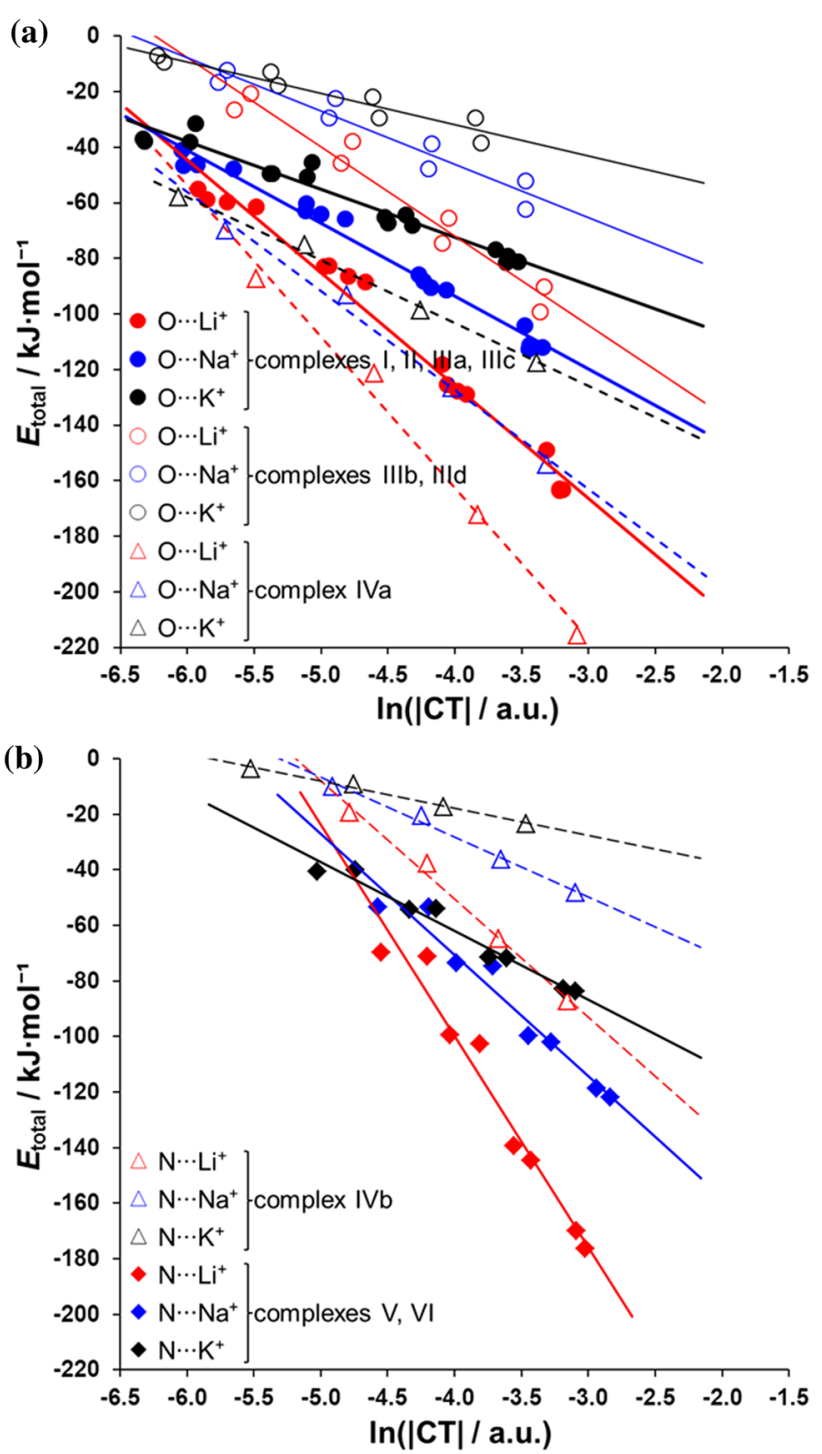

Fig. 1 Dependences of the total interaction energy, $E_{\text {total }}$, on the magnitude of transferred charge, $\ln (|\mathrm{CT}|)$, for complexes of cations with the oxygen (a) and nitrogen (b) atoms of solvents
Table 2 Slope $(a)$, intercept $(b)$, their standard error values $\left(s_{a}, s_{b}\right)$ and coefficient of determination $\left(R^{2}\right)$ related to the linear trendlines given in Fig. 1

\begin{tabular}{|c|c|c|c|c|c|c|}
\hline \multirow[t]{2}{*}{ Complex } & \multirow[t]{2}{*}{ Interaction } & \multicolumn{5}{|c|}{$E_{\mathrm{total}}=a \ln (\mathrm{CT})+b$} \\
\hline & & $a$ & $s_{a}$ & $b$ & $s_{b}$ & $R^{2}$ \\
\hline \multirow[t]{3}{*}{ I, II, IIIa, IIIc } & $\mathrm{O} \cdots \mathrm{Li}^{+}$ & -40.7 & 1.5 & -288.4 & 7.0 & 0.981 \\
\hline & $\mathrm{O} \cdots \mathrm{Na}^{+}$ & -26.3 & 0.9 & -198.6 & 4.4 & 0.982 \\
\hline & $\mathrm{O} \cdots \mathrm{K}^{+}$ & -17.2 & 1.0 & -141.3 & 5.1 & 0.952 \\
\hline \multirow[t]{3}{*}{ IIIb, IIId } & $\mathrm{O} \cdots \mathrm{Li}^{+}$ & -32.1 & 2.8 & -200.4 & 12.8 & 0.955 \\
\hline & $\mathrm{O} \cdots \mathrm{Na}^{+}$ & -19.2 & 2.2 & -122.9 & 10.2 & 0.927 \\
\hline & $\mathrm{O} \cdots \mathrm{K}^{+}$ & -11.2 & 1.5 & -76.6 & 7.5 & 0.904 \\
\hline \multirow[t]{3}{*}{ IVa } & $\mathrm{O} \cdots \mathrm{Li}^{+}$ & -54.4 & 4.2 & -380.4 & 18.3 & 0.988 \\
\hline & $\mathrm{O} \cdots \mathrm{Na}^{+}$ & -35.6 & 2.7 & -270.1 & 12.2 & 0.989 \\
\hline & $\mathrm{O} \cdots \mathrm{K}^{+}$ & -22.6 & 1.2 & -193.8 & 5.8 & 0.994 \\
\hline \multirow[t]{3}{*}{$\mathrm{IVb}$} & $\mathrm{N} \cdots \mathrm{Li}^{+}$ & -42.5 & 2.8 & -220.6 & 11.2 & 0.991 \\
\hline & $\mathrm{N} \cdots \mathrm{Na}^{+}$ & -21.5 & 1.5 & -114.3 & 5.9 & 0.991 \\
\hline & $\mathrm{N} \cdots \mathrm{K}^{+}$ & -9.8 & 0.7 & -57.2 & 3.2 & 0.990 \\
\hline \multirow[t]{3}{*}{$\mathrm{V}, \mathrm{VI}$} & $\mathrm{N} \cdots \mathrm{Li}^{+}$ & -76.1 & 6.3 & -404.0 & 23.6 & 0.960 \\
\hline & $\mathrm{N} \cdots \mathrm{Na}^{+}$ & -43.7 & 4.0 & -245.2 & 14.6 & 0.952 \\
\hline & $\mathrm{N} \cdots \mathrm{K}^{+}$ & -24.8 & 1.8 & -161.2 & 7.2 & 0.970 \\
\hline
\end{tabular}

\section{Interactions with anions}

Figure 2 shows the dependences of the $E_{\text {total }}$ values on the magnitude of CT for anions interacting with the acidic centers of solvent molecules (i.e., $\mathrm{OH}$ and $\mathrm{NH}$ groups in Fig. 2a, b, respectively), including the data for non-equilibrium interactions. Similar to the interactions with cations, the linear regressions have good determination coefficients, $R^{2}$, with the worst value equal to 0.927 . Statistical data for all regression lines of Fig. 2 are given in Table 3, selected parameters obtained for equilibrium complexes are presented in Table 4, whereas Tables S5-S7 (SI) contain also the data for simulated complexes in which anions were gradually moved away by 50, 100 and $150 \mathrm{pm}$ from the equilibrium position and linearity of the hydrogen bond was imposed.

During the optimization procedure, it turned out that in the case of equilibrium complexes of formic acid and formamide with the $\mathrm{F}^{-}$anion (3a, 3b, $\mathbf{4 a}$ and $\mathbf{4 b}$ systems), a proton transfer takes place and complexes with $\mathrm{O}^{-} / \mathrm{N}^{--}$ ..HF interactions are formed. They were not included in further discussions due to the different types of interaction.

Inspection of Fig. 2 indicates that for the same groups of complexes (Table 3), the slopes of regression lines clearly change in the order $\mathrm{F}^{-}, \mathrm{Cl}^{-}, \mathrm{Br}^{-}$, i.e., down the periodic group in a similar manner as observed for interactions with cations. However, an analysis of the topological characteristics at BCPs revealed a different nature of interactions with anions than with cations. In the anion case, the 

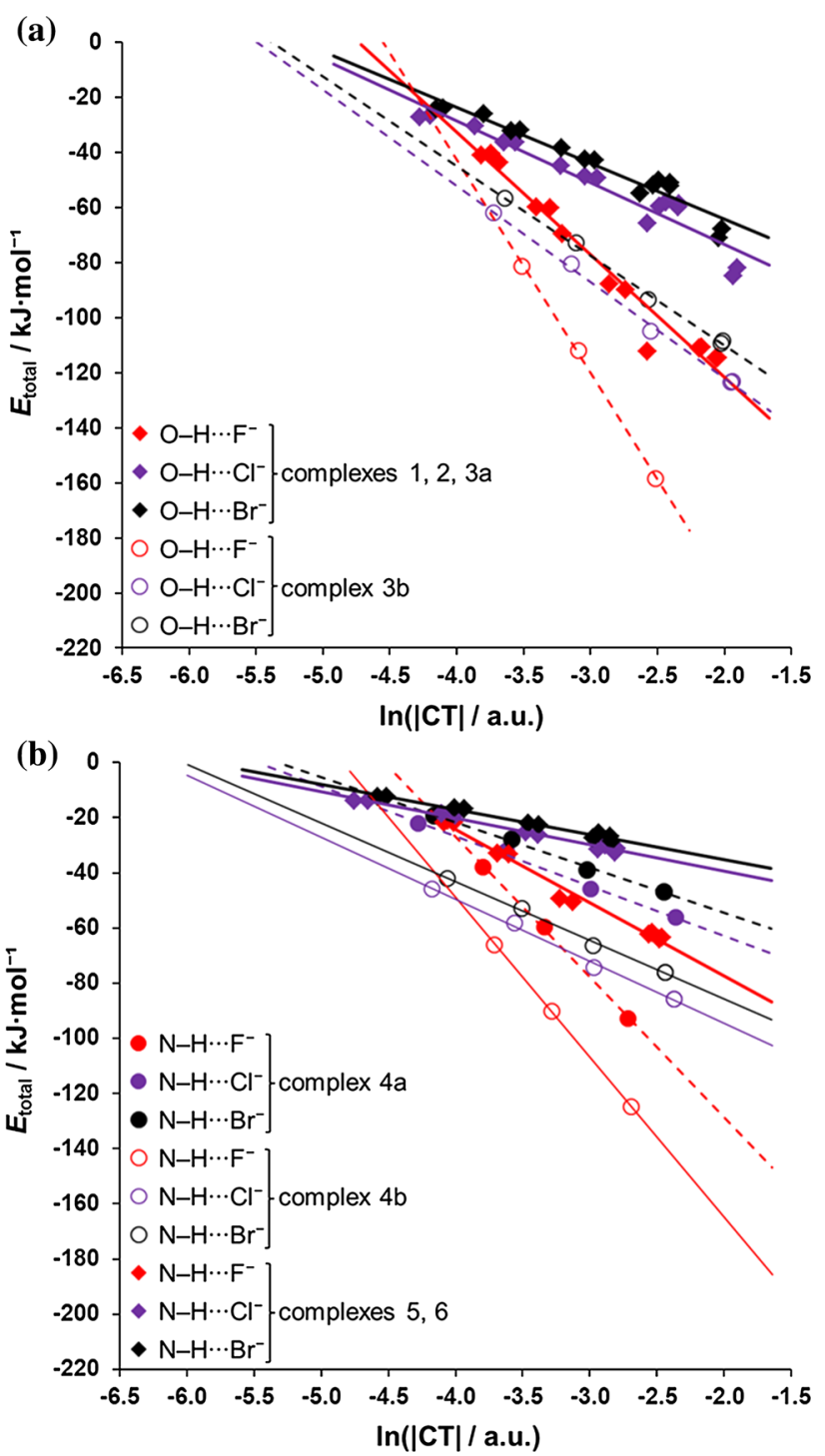

Fig. 2 Dependences of the total interaction energy, $E_{\text {total, }}$, on the magnitude of CT for the hydroxy- (a) and amino- (b) groups interacting with the anions $\mathrm{F}^{-}, \mathrm{Cl}^{-}$and $\mathrm{Br}^{-}$

positive values of the Laplacian in combination with larger values of the $\mid V_{\mathrm{BCP}} / G_{\mathrm{BCP}}$ ratio (mostly $>1$ ) indicate a partially covalent character of these interactions [35].

The energy of electrostatic interactions with monovalent ions should depend on the reciprocal of ionic radius, which, for example in solution, is described in the simplest way by the Born equation [37]. Therefore, the slopes of lines shown in Figs. 1 and 2, representing the change of the interaction energy of the solvent molecule with ion caused by the unit change of $\ln (|\mathrm{CT}|)$, should be proportional to the reciprocal of ionic radius. Such plots for cations are shown in Fig. 3a, separately for $\mathrm{O} \cdots \mathrm{M}^{+}$interactions (complexes $\mathbf{I}$, II, IIIa, and IIIc in Table 2) and for $\mathrm{N} \cdots \mathrm{M}^{+}$interactions (complexes $\mathbf{V}$ and $\mathbf{V I}$ in Table 2). Similar plots for anions
Table 3 Slope $(a)$, intercept $(b)$, their standard error values $\left(s_{a}, s_{b}\right)$ and coefficient of determination $\left(R^{2}\right)$ related to the linear trendlines given in Fig. 2

\begin{tabular}{|c|c|c|c|c|c|c|}
\hline \multirow[t]{2}{*}{ Complex } & \multirow[t]{2}{*}{ Interaction } & \multicolumn{5}{|c|}{$E_{\text {total }}=a \ln (-\mathrm{CT})+b$} \\
\hline & & $a$ & $s_{a}$ & $b$ & $s_{b}$ & $R^{2}$ \\
\hline \multirow[t]{3}{*}{$1,2,3 \mathrm{a}$} & $\mathrm{O}-\mathrm{H} \cdots \mathrm{F}^{-}$ & -44.4 & 2.6 & -210.4 & 7.6 & 0.965 \\
\hline & $\mathrm{O}-\mathrm{H} \cdots \mathrm{Cl}^{-}$ & -22.4 & 1.7 & -118.1 & 5.4 & 0.927 \\
\hline & $\mathrm{O}-\mathrm{H} \cdots \mathrm{Br}^{-}$ & -20.2 & 1.4 & -104.6 & 4.2 & 0.944 \\
\hline \multirow[t]{3}{*}{$3 b$} & $\mathrm{O}-\mathrm{H} \cdots \mathrm{F}^{-}$ & -77.4 & 2.1 & -352.6 & 6.3 & 0.999 \\
\hline & $\mathrm{O}-\mathrm{H} \cdots \mathrm{Cl}^{-}$ & -35.0 & 1.1 & -192.0 & 3.0 & 0.997 \\
\hline & $\mathrm{O}-\mathrm{H} \cdots \mathrm{Br}^{-}$ & -32.6 & 1.0 & -175.2 & 2.9 & 0.997 \\
\hline \multirow[t]{3}{*}{$4 \mathrm{a}$} & $\mathrm{N}-\mathrm{H} \cdots \mathrm{F}^{-}$ & -50.9 & 1.6 & -230.6 & 5.3 & 0.999 \\
\hline & $\mathrm{N}-\mathrm{H} \cdots \mathrm{Cl}^{-}$ & -18.1 & 0.9 & -98.9 & 3.1 & 0.995 \\
\hline & $\mathrm{N}-\mathrm{H} \cdots \mathrm{Br}^{-}$ & -16.5 & 0.8 & -87.5 & 2.6 & 0.995 \\
\hline \multirow[t]{3}{*}{$4 b$} & $\mathrm{~N}-\mathrm{H} \cdots \mathrm{F}^{-}$ & -57.9 & 0.4 & -280.8 & 1.3 & 1.000 \\
\hline & $\mathrm{N}-\mathrm{H} \cdots \mathrm{Cl}^{-}$ & -22.5 & 0.8 & -139.5 & 2.5 & 0.996 \\
\hline & $\mathrm{N}-\mathrm{H} \cdots \mathrm{Br}^{-}$ & -21.3 & 0.7 & -128.2 & 2.3 & 0.997 \\
\hline \multirow[t]{3}{*}{5,6} & $\mathrm{~N}-\mathrm{H} \cdots \mathrm{F}^{-}$ & -26.5 & 1.2 & -130.4 & 3.8 & 0.985 \\
\hline & $\mathrm{N}-\mathrm{H} \cdots \mathrm{Cl}^{-}$ & -9.6 & 0.4 & -58.8 & 1.3 & 0.988 \\
\hline & $\mathrm{N}-\mathrm{H} \cdots \mathrm{Br}^{-}$ & -9.1 & 0.4 & -53.3 & 1.4 & 0.986 \\
\hline
\end{tabular}

are shown in Fig. 3b, separately for $\mathrm{O}-\mathrm{H} \cdots \mathrm{X}^{-}$interactions (complexes 1, 2, and 3a in Table 3) and for $\mathrm{N}-\mathrm{H} \cdots \mathrm{X}^{-}$ interactions (complexes 5 and $\mathbf{6}$ in Table 3). Good regressions were obtained in all cases with high determination coefficients, and the statistical parameters obtained are given in Table S8 (SI). It is also interesting to note that more negative values of slopes are observed for cations interacting with the $\mathrm{N}$ atom (solid diamonds in Fig. 3a) than with the $\mathrm{O}$ atom (solid circles in Fig. 3a); it corresponds to the more negative interaction energy, $E_{\text {total }}$, as well as the more negative value of CT (Table 1). The observed feature can be explained by a higher electronegativity of the oxygen atom than that of the nitrogen atom. Thus, for $\mathrm{O} \cdots \mathrm{M}^{+}$complexes, a negative charge is strongly attracted by the $\mathrm{O}$ atom and the $\mathrm{CT}$ to cation is smaller than that for $\mathrm{N} \cdots \mathrm{M}^{+}$complexes, resulting in a smaller absolute value of the $E_{\text {total }}$. The greatest difference is observed for the smallest $\mathrm{Li}^{+}$cation which has the strongest attraction ability.

A reverse situation is observed for anions. The bonding of the hydrogen atom with the more electronegative oxygen atom is stronger than that with the nitrogen atom, and thus, a more negative charge is transferred from an anion to the more acidic $\mathrm{OH}$ group in $\mathrm{O}-\mathrm{H} \cdots \mathrm{X}^{-}$complexes, resulting in more negative values of $E_{\text {total }}$ and of slopes $a$, than those for $\mathrm{N}-\mathrm{H} \cdots \mathrm{X}^{-}$complexes. In accordance with this explanation, the same difference in electronegativity of the $\mathrm{O}$ and $\mathrm{N}$ atoms results in similar differences in slopes of both lines (for cations $\Delta=3.1$ 
Table 4 Selected parameters of $\mathrm{O}-\mathrm{H} / \mathrm{N}-\mathrm{H} \cdots \mathrm{X}^{-}$and $\mathrm{O}^{-} /$ $\mathrm{N}^{-} \ldots \mathrm{HF}$ interactions of solvents molecules with anions $\mathrm{X}^{-}=\mathrm{F}^{-}, \mathrm{Cl}^{-}, \mathrm{Br}^{-}$in equilibrium complexes

\begin{tabular}{|c|c|c|c|c|c|}
\hline Complex & Interaction & $\begin{array}{l}d_{\mathrm{H} \cdots \mathrm{X}^{-}} \\
(\mathrm{pm})\end{array}$ & $E_{\text {total }}\left(\mathrm{kJ} \mathrm{mol}^{-1}\right)$ & $\left|V_{\mathrm{BCP}}\right| / G_{\mathrm{BCP}}$ & CT (a.u.) \\
\hline \multirow[t]{3}{*}{1} & $\mathrm{O}-\mathrm{H} \cdots \mathrm{F}^{-}$ & 139.9 & -111.0 & 1.350 & -0.112 \\
\hline & $\mathrm{O}-\mathrm{H} \cdots \mathrm{Cl}^{-}$ & 215.6 & -59.5 & 1.022 & -0.083 \\
\hline & $\mathrm{O}-\mathrm{H} \cdots \mathrm{Br}^{-}$ & 236.0 & -52.0 & 0.958 & -0.079 \\
\hline \multirow[t]{3}{*}{2} & $\mathrm{O}-\mathrm{H} \cdots \mathrm{F}^{-}$ & 135.1 & -114.5 & 1.429 & -0.127 \\
\hline & $\mathrm{O}-\mathrm{H} \cdots \mathrm{Cl}^{-}$ & 211.8 & -59.8 & 1.084 & -0.096 \\
\hline & $\mathrm{O}-\mathrm{H} \cdots \mathrm{Br}^{-}$ & 233.8 & -52.1 & 0.997 & -0.090 \\
\hline \multirow[t]{3}{*}{$3 a$} & $\mathrm{O}^{-} \cdots \mathrm{HF}^{(\mathrm{a})}$ & 100.1 & -112.0 & 1.434 & 0.114 \\
\hline & $\mathrm{O}-\mathrm{H} \cdots \mathrm{Cl}^{-}$ & 210.7 & -84.8 & 1.502 & -0.145 \\
\hline & $\mathrm{O}-\mathrm{H} \cdots \mathrm{Br}^{-}$ & 210.8 & -71.0 & 1.332 & -0.130 \\
\hline \multirow[t]{3}{*}{$3 b$} & $\mathrm{O}^{-} \cdots \mathrm{HF}^{(\mathrm{a})}$ & 103.4 & -117.0 & 1.641 & 0.134 \\
\hline & $\mathrm{O}-\mathrm{H} \cdots \mathrm{Cl}^{-}$ & 192.0 & -123.6 & 1.426 & -0.142 \\
\hline & $\mathrm{O}-\mathrm{H} \cdots \mathrm{Br}^{-}$ & 213.7 & -109.4 & 1.294 & -0.132 \\
\hline \multirow[t]{3}{*}{$4 a$} & $\mathrm{~N}^{-} \cdots \mathrm{HF}^{(\mathrm{a})}$ & 107.9 & -129.4 & 2.141 & 0.540 \\
\hline & $\mathrm{N}-\mathrm{H} \cdots \mathrm{Cl}^{-(\mathrm{b})}$ & - & - & - & - \\
\hline & $\mathrm{N}-\mathrm{H} \cdots \mathrm{Br}^{-(b)}$ & - & - & - & - \\
\hline \multirow[t]{3}{*}{$4 b$} & $\mathrm{~N}^{-} \cdots \mathrm{HF}^{(\mathrm{a})}$ & 118.8 & -135.3 & 3.357 & 0.233 \\
\hline & $\mathrm{N}-\mathrm{H} \cdots \mathrm{Cl}^{-}$ & 187.8 & -85.8 & 1.120 & -0.093 \\
\hline & $\mathrm{N}-\mathrm{H} \cdots \mathrm{Br}^{-}$ & 232.0 & -76.0 & 1.031 & -0.087 \\
\hline \multirow[t]{3}{*}{5} & $\mathrm{~N}-\mathrm{H} \cdots \mathrm{F}^{-}$ & 159.4 & -64.0 & 1.150 & -0.084 \\
\hline & $\mathrm{N}-\mathrm{H} \cdots \mathrm{Cl}^{-}$ & 236.1 & -32.7 & 0.850 & -0.060 \\
\hline & $\mathrm{N}-\mathrm{H} \cdots \mathrm{Br}^{-}$ & 257.6 & -28.5 & 0.835 & -0.059 \\
\hline \multirow[t]{3}{*}{6} & $\mathrm{~N}-\mathrm{H} \cdots \mathrm{F}^{-}$ & 160.6 & -62.2 & 1.147 & -0.077 \\
\hline & $\mathrm{N}-\mathrm{H} \cdots \mathrm{Cl}^{-}$ & 239.6 & -31.5 & 0.827 & -0.053 \\
\hline & $\mathrm{N}-\mathrm{H} \cdots \mathrm{Br}^{-}$ & 261.3 & -27.4 & 0.815 & -0.051 \\
\hline
\end{tabular}

(a) Proton transfer takes place

(b) Complexes $4 \mathrm{~b}$ are more stable than $4 \mathrm{a}$

Fig. 3 Dependence of slopes $a$ from Tables 2 and 3 on the reciprocal of the Pauling ionic radius [38] for cations (a) and anions (b)
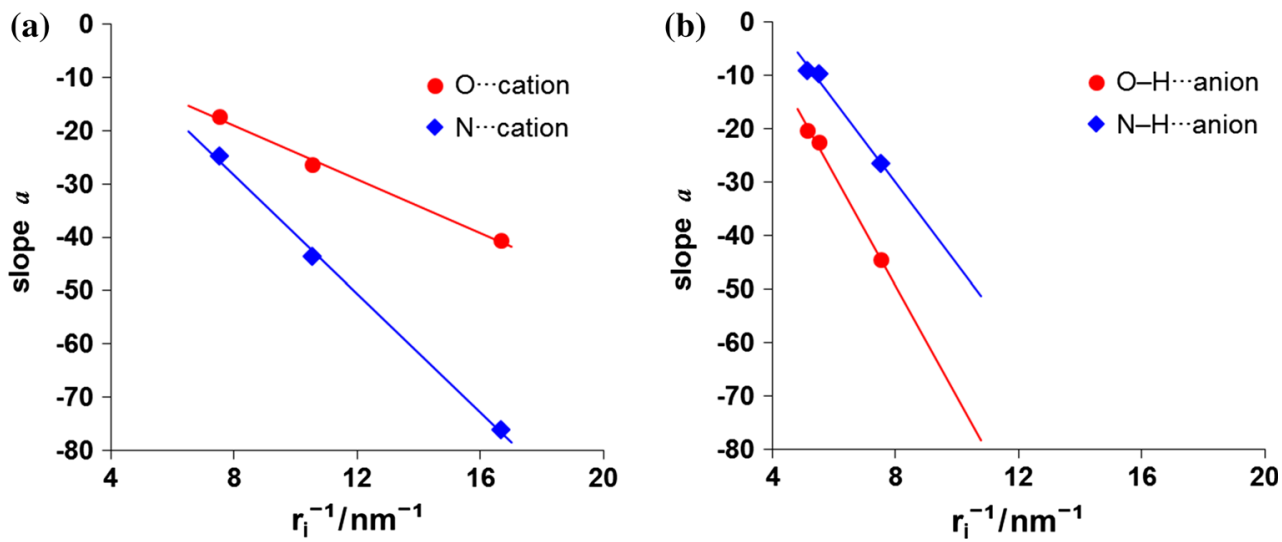

and for anions $\Delta=2.7$; cf., Table S8), but the first difference is slightly higher because cations interact directly with oxygen atoms.

The results obtained support the classic view that solute-solvent interactions can be described in terms of Lewis acid-base interactions [8-13]. However, these interactions can be considered as a charge transfer, and thus, solvent acidity/basicity is a dynamic property depending not only on the nature of a solvent molecule with its proper acidic and basic centers but also on the acidity/basicity of the interacting ion. The quantumchemical approach used here offers the calculation of $E_{\text {total }}$ as an absolute measure of Lewis acidity/basicity for each system including ion and solvent molecule in a vacuum. The validity of these results will be checked in the next part by comparison with experimental data. 


\section{Interrelation between $E_{\text {total }}$ and enthalpies of ion solvation}

The calculated binding energies for different ions were correlated with experimental enthalpies of ion solvation, $\Delta H_{\mathrm{i}, \mathrm{o} \text { olv }}^{\mathrm{o}}$. Their values were obtained from standard molar enthalpies of transfer $\Delta_{\mathrm{tr}} H^{\mathrm{o}}(i, W \rightarrow S)$ of a given ion from water to nonaqueous solvents (based on the extrathermodynamic assumption stating that the contributions of tetraphenylarsonium cation and tetraphenylborate anion of a reference electrolyte are the same) [39], and absolute standard molar enthalpies of hydration at $298.15 \mathrm{~K}$ of a given ion obtained by Marcus [40a] from conventional values, assuming the value for the hydrogen ion as equal to $\Delta H_{\mathrm{i}, \mathrm{solv}}^{\mathrm{o}}\left(\mathrm{H}^{+}\right)=-1094 \mathrm{~kJ} \mathrm{~mol}^{-1}$. Only for water, methanol, and formamide, $\Delta H_{\mathrm{i}, \text { solv }}^{\mathrm{o}}$ values are available for all ions under investigation, while for ammonia, data are available for five ions, excluding the fluoride ion. Total interaction energies for complexation with three cations correlate well with $\Delta H_{\mathrm{i} \text {,solv }}^{\mathrm{o}}$ as shown in Fig. 4. The statistically significant correlation is described by Eq. (1):

$E_{\text {total }}=0.40( \pm 0.04) \Delta H_{\mathrm{i} \text {,solv }}^{\mathrm{o}}+60( \pm 16)$

where errors based on the Student's distribution with a confidence level of $\alpha=0.05$ are given in parentheses, the determination coefficient $R^{2}=0.984$ and the value of Snedecor test $F=619.3$, whereas its critical value for $\alpha=0.01$ is $F_{\mathrm{c}}(99 \%, 1,10)=10.0$.

For formamide, mean values of the total energy calculated for interactions of each cation with oxygen and with nitrogen atoms were used in the plot. For each cation, these values are the most deviating points from the correlation line shown in Fig. 4. Nevertheless, a good correlation obtained can suggest that the probability of interaction of

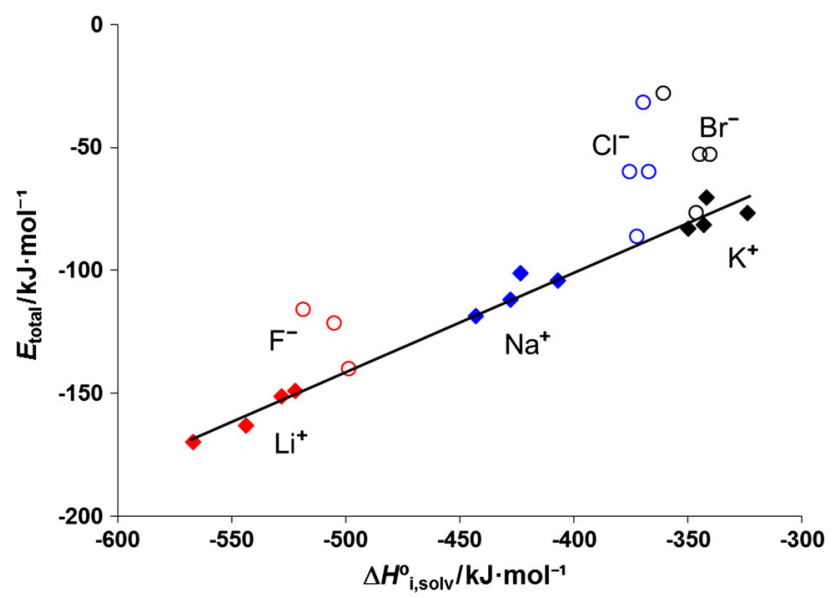

Fig. 4 Correlation between the total interaction energy and the enthalpy of solvation of ions. Solid squares correspond to cations, and open circles to anions. A linear trendline for cations is shown cation with both donor atoms ( $\mathrm{N}$ and $\mathrm{O}$ ) in the molecule of formamide is approximately the same.

It should be added that there is no good linear correlation between the total energies and the standard molar Gibbs free energies of solvation, $\Delta G_{\mathrm{i}, \mathrm{solv}}^{\mathrm{o}}$. This shows the important role played by the entropy term in experimental conditions in which interactions between solvent molecules also occur. These interactions are not taken into account in theoretical models.

For all three anions, there is no correlation with $\Delta H_{\mathrm{i}, \text { solv }}^{\mathrm{o}}$, as shown in Fig. 4 (open circles, all calculated values are shown). However, the points for each anion, interacting with formamide, lay correctly in the regression line obtained for cations. For other solvents, the points for three anions lay in separate straight lines indicating the participation of an additional effect.

Before proceeding to a detailed discussion of anions, it should be emphasized that the experimental $\Delta H_{\mathrm{i}, \text { solv }}^{\mathrm{o}}$ and $\Delta G_{\mathrm{i}, \text { solv }}^{\mathrm{o}}$ values are less negative [41a] than those calculated from the Born [37] equation which considers only "pure" electrostatic interactions in a solvent treated as a dielectric continuum. The above-mentioned discrepancy between experimental and calculated results was usually explained [41b] by a significant disruption of the solvent structure near the ion. Thus, the negative enthalpy of ion-solvent interactions is reduced by the energy which is necessary for changing solvent-solvent interactions in the presence of an ion. This effect was described by the effective distance $\delta_{\mathrm{s}}$ over which the ionic radius must be increased to account for the disruption of solvent structure around this ion. The correction term $\delta_{\mathrm{s}}$ depends on the solvent and is different for cations and anions. A comparison of experimental $\Delta G_{\mathrm{i}, \text { olv }}^{\mathrm{o}}$ values of monovalent, monatomic cations and anions measured in 17 solvents showed that $\delta_{\mathrm{s}}$ depends linearly on the solvent basicity (given by the donor number DN $[14,15]$ ) and solvent acidity (given by the Dimroth and Reichardt $E_{T}$ parameter [5]) for cations and anions, respectively [42]. However, in our quantum-chemical calculations, the absolute values of $E_{\text {total }}$ are substantially smaller than the $\Delta H_{\mathrm{i}, \mathrm{o} o l v}^{\mathrm{o}}$ values, which is opposite to calculations from the Born model.

In a more advanced model of ion solvation, the energy of solvent-solvent interactions should be taken into account beside the energy of ion-solvent interactions. In the simplest approach of Fawcett [41c, 43], it is included in the term $f_{\mathrm{dd}}$ describing how the attractive ion-solvent energy is reduced by repulsive dipole-dipole interactions between solvent molecules. Thus, the Gibbs energy of solvation $\Delta G_{\mathrm{i}, \mathrm{solv}}^{\mathrm{o}}$ of an ion with radius $r_{i}$ and charge $Z_{i} e_{\mathrm{o}}$ in infinitely dilute solutions can be approximately described by Eq. (2) similar to the Born equation but with two additional correction terms, $\delta_{\mathrm{s}}$ and $f_{\mathrm{dd}}$ : 
$\Delta G_{\mathrm{i}, \mathrm{solv}}^{\mathrm{o}}=-\left(N_{\mathrm{A}} Z_{i}^{2} e_{\mathrm{o}}^{2}\right)\left(1-1 / \varepsilon_{\mathrm{s}}\right)\left(1-f_{\mathrm{dd}}\right) / 8 \pi \varepsilon_{\mathrm{o}}\left(r_{i}+\delta_{\mathrm{s}}\right)$

where $N_{\mathrm{A}}$ is Avogadro's number, and $\varepsilon_{\mathrm{s}}$ and $\varepsilon_{\mathrm{o}}$ are the dielectric permittivity of the solvent and free space, respectively. Equation (2) is in agreement with rigorous results obtained in terms of the mean spherical approximation (MSA), the simplest non-primitive model of electrolyte solutions based on statistical mechanical consideration of the ion-dipole mixture represented by hard spheres. Moreover, in Eq. (2), the $\delta_{\mathrm{s}}$ and $f_{\text {dd }}$ terms can be treated as adjustable parameters describing all specific chemical interactions in solutions. Thus, the $f_{\mathrm{dd}}$ term describes not only the contribution of energy of dipoledipole interactions between the solvent molecules to the solvation of an ion, but for protic solvents, it also includes the hydrogen bond formation. In particular, Fawcett found for monatomic ions in aqueous solutions [41d, 43] that the $\delta_{\mathrm{s}}$ term is important only for cations and the $f_{\text {dd }}$ term only for anions. Recently, the experimental $\Delta G_{\mathrm{i}, \text { solv }}^{\mathrm{o}}$ values for monatomic cations in six protic and ten aprotic solvents were analyzed in terms of Eq. (2) [44]. It was shown that neither of the correction terms can be neglected. Moreover, the $\delta_{\mathrm{s}}$ term is inversely proportional to solvent basicity and to the $f_{\text {dd }}$ term. This means that solvent-solvent interactions play a dual role, influencing both $\delta_{\mathrm{s}}$ and $f_{\text {dd }}$ parameters. On the one hand, they make a disruption of solvent structure around an ion more difficult decreasing the $\delta_{\mathrm{s}}$ term and thus increasing the absolute value of $\Delta G_{\mathrm{i}, \mathrm{o} \text { olv }}^{\mathrm{o}}$. The same behavior occurs for stronger ion-solvent interactions. On the other hand, stronger solvent-solvent interactions make the ion-solvent attraction more difficult, diminishing $\Delta G_{\mathrm{i}, \text { olv }}^{\mathrm{o}}$ by the $f_{\mathrm{dd}}$ contribution [44]. It was impossible to perform a similar statistically reasonable analysis for anions [44] because of the lack of experimental $\Delta G_{\mathrm{i}, \text { olv }}^{\mathrm{o}}$ data for a sufficient number of systems. However, at least for protic solvents, one can expect the dominant role of solvent-solvent interactions expressed by the $f_{\text {dd }}$ term (including dipole-dipole as well as hydrogen bonding) in solvation of anions, as suggested by Fawcett for aqueous solutions [41d, 43].

One possible experimental measure of such interactions is the molar heat of vaporization, $\Delta H_{\mathrm{vap}}$, for a given solvent. The values of $\Delta H_{\text {vap }}$ (in $\mathrm{kJ} \mathrm{mol}^{-1}$ at $298 \mathrm{~K}$ with the exception of ammonia where $\Delta H_{\text {vap }}$ was given at the normal boiling point) are tabulated by Marcus [40b]. Indeed, the use of the two-parameter regression of $E_{\text {total }}$ calculated for anions gave a good correlation as shown in Fig. 5 and described by Eq. (3):

$$
\begin{aligned}
E_{\text {total }}= & 0.42( \pm 0.07) \Delta H_{\mathrm{i}, \text { solv }}^{\mathrm{o}}-1.2( \pm 0.3) \Delta H_{\mathrm{vap}} \\
& +148( \pm 29)
\end{aligned}
$$

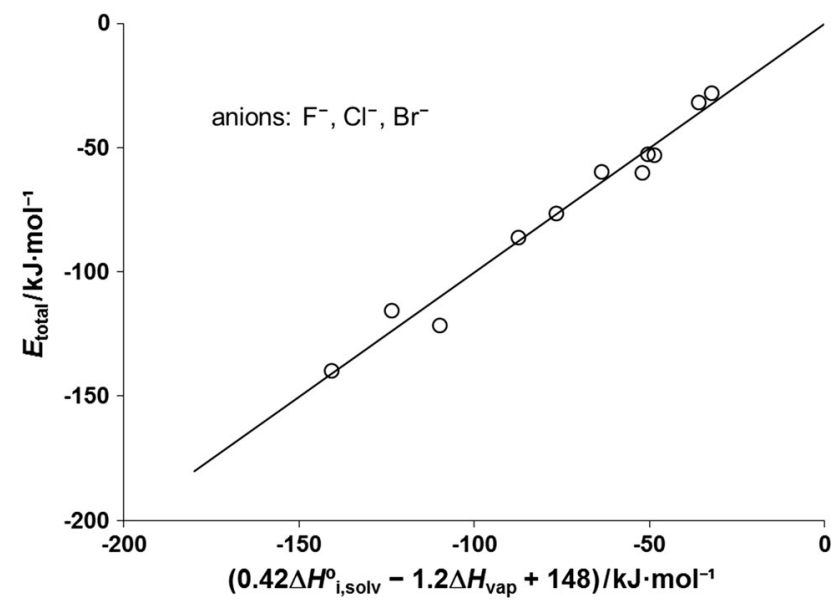

Fig. 5 Correlation between the total interaction energy, $E_{\text {total }}$, and the enthalpy of ion solvation and the heat of vaporization of solvents according to Eq. (3) with $R^{2}=0.988$. The theoretical line with a unit slope is shown

It holds with the determination coefficient of $R^{2}=0.976$ and the value of Snedecor test $F=160.1$, whereas its critical value for $\alpha=0.01$ is $F_{\mathrm{c}}(99 \%, 1,8)=11.3$. Moreover, the addition of the second $\Delta H_{\text {vap }}$ term to Eq. (1) is important with the probability of $99.73 \%$ as indicated by the statistical test $F_{\text {imp }}$ [45].

It is interesting to compare Eq. (1) for the solvation of cations and Eq. (3) for anions. The regression coefficients at $\Delta H_{\mathrm{i}, \mathrm{o} \text { olv }}^{\mathrm{are}}$ approximately the same. In both cases, the calculated interaction energy follows the experimental values with a change in an ion-solvent system, but the change in $E_{\text {total }}$ is 2.5 times weaker than that of the experimental values.

This can be explained by the fact that quantum-chemical calculations were performed for isolated complexes (ionsolvent molecule) in vacuum and not in a dielectric medium with increasing electrostatic interactions. Moreover, it is evident that solvent-solvent interactions have a substantial effect on experimental $\Delta H_{\mathrm{i}, \text { solv }}^{\mathrm{o}}$ values only in the case of anions. It is worth mentioning that the addition of the $\Delta H_{\text {vap }}$ term to $E_{\text {total }}$ decreases the absolute value of the latter, thus increasing the discrepancy between the absolute values of $\Delta H_{\mathrm{i}, \text { solv }}^{\mathrm{o}}$ and $E_{\text {total }}$ energy, i.e., shifting points for anions upward in Fig. 4. This is in accordance with the predicted role of the $f_{\text {dd }}$ term in Eq. (2) suggested by Fawcett [41d, 43] only for the hydration of anions.

Finally, it should be emphasized that the absolute values of $E_{\text {total }}$ are much smaller than the experimental $\Delta H_{\mathrm{i}, \text { olv }}^{\mathrm{o}}$ values for both kinds of ions, and this difference is greater for anions. These differences are independent of the nature of an ion as well as of a solvent, and they are expressed by intercepts: 60 for cations in Eq. (1) and 148 for anions in 
Eq. (3). Certainly, they reflect simplifications in the applied model of calculations, but the results obtained are not sufficient for a more detailed interpretation.

It should also be added that the difference between solvation energies of cations and anions of the same magnitude was already discussed by Buckingham [46] taking into account ion-quadrupole attractions (given by the additional term $N_{\mathrm{A}} Z_{i} e_{\mathrm{o}} \theta_{\mathrm{s}} r_{i}^{-3}$ ) and mutual interactions of solvent molecules which involve solvent electrical quadrupole moments $\theta_{\mathrm{s}}$. However, the proposed model [46] was practically not used because of the lack of proper $\theta_{\mathrm{s}}$ values for solvents [40].

\section{Conclusions}

The Lewis basicity and acidity of solvent molecules (water, methanol, formic acid, formamide, methylamine, and ammonia) was studied in the gas phase. For this purpose, the binding energy $\left(E_{\text {total }}\right)$ and QTAIM parameters (CT and $\left.\left|V_{\mathrm{BCP}}\right| / G_{\mathrm{BCP}}\right)$ were used to characterize intermolecular interactions between a particular active center of the solvent molecule and the cation or anion, respectively. It was shown that:

1. The obtained dependences of $E_{\text {total }}$ on $\ln (|\mathrm{CT}|)$ are linear and can be identified with a well-known thermodynamic relation between Gibbs free energy and the equilibrium constant. Therefore, the CT parameter has a similar physical meaning as the equilibrium constant or the reaction quotient, if the equilibrium was not reached.

2. The slope values of the linear equations $E_{\text {total }}$ versus $\ln (|\mathrm{CT}|)$ for particular interactions change in the order of $\mathrm{Li}^{+}, \mathrm{Na}^{+}, \mathrm{K}^{+}$and $\mathrm{F}^{-}, \mathrm{Cl}^{-}, \mathrm{Br}^{-}$. Additionally, these slopes, representing the change of the energy of solvent-ion interactions caused by the unit change of $\ln (|\mathrm{CT}|)$, are proportional to the reciprocal of ion radius.

3. The calculated values of the $\left|V_{\mathrm{BCP}}\right| / G_{\mathrm{BCP}}$ ratio reveal a pure closed-shell character for intermolecular interactions of the solvent molecule with cations, and a partially covalent character for interactions with anions (in equilibrium $\mathrm{H}$-bonded complexes).

4. The calculated binding energies of the interactions with cations/anions were compared with available experimental quantities for individual ions. For cations, significant linear relationships between $E_{\text {total }}$ and the experimental molar enthalpy of ion solvation, $\Delta H_{\mathrm{i}, \text { solv }}^{\mathrm{o}}$, were obtained. However, for anions, the addition of the second explanatory parameter, the molar heat of vaporization of a solvent, $\Delta H_{\text {vap }}$, was necessary for the correlation with $\Delta H_{\mathrm{i}, \mathrm{o} \text { olv }}^{\mathrm{o}}$ values. This indicates an important influence of solvent-solvent interactions (liquid structure) on the energy of anionsolvent attractions, in agreement with the literature.

Summing up, the quantum-chemical approach can be used to identify in a quantitative and absolute way the Lewis basicity and acidity of particular active centers of solvent molecules interacting with simple ions.

Acknowledgments Calculations using the Gaussian 09 set of codes were carried out in the Wroclaw Center for Networking and Supercomputing (http://www.wcss.wroc.pl) and the Interdisciplinary Center for Mathematical and Computational Modeling in Warsaw (http:// www.icm.edu.pl). Access to HPC machines and licensed software is gratefully acknowledged. H.S. thanks the Warsaw University of Technology for supporting this work.

Open Access This article is distributed under the terms of the Creative Commons Attribution 4.0 International License (http://crea tivecommons.org/licenses/by/4.0/), which permits unrestricted use, distribution, and reproduction in any medium, provided you give appropriate credit to the original author(s) and the source, provide a link to the Creative Commons license, and indicate if changes were made.

\section{References}

1. Hammett LP (1970) Physical Organic Chemistry. McGraw-Hill, New York

2. Kirkwood JG (1934) J Chem Phys 2:351-361

3. West W, Edwards RT (1937) J Chem Phys 5:14-22

4. Bauer E, Magat M (1938) J Phys Radium 9:319-330

5. Reichardt C, Welton T (2011) Solvents and solvent effects in organic chemistry, 4th edn. Wiley- $\mathrm{VCH}$, Weinheim, (a) ch 2.2, (b) p 418, (c) p 433

6. Koppel IA, Palm VA (1972) In: Chapman NB, Shorter J (eds) Advances in linear free energy relationships, chap 5. Plenum, New York, pp 203-280

7. Hildebrand JH, Prausnitz JM, Scott RL (1970) Regular and related solutions. Van Nostrand-Reinhold, Princeton

8. Drago RS, Wayland BB (1965) J Am Chem Soc 87:3571-3577

9. Drago RS (1980) Coord Chem Rev 33:251-277

10. Krygowski TM, Fawcett WR (1975) J Am Chem Soc 97:2143-2148

11. Fawcett WR, Krygowski TM (1975) Austr J Chem 28:2115-2124

12. Catalán J, Díaz C, López V, Pérez P, de Paz J-LG, Rodriguez JG (1996) Liebigs Ann 1996(11):1785-1794

13. Catalán J, Díaz C (1997) Liebigs Ann 1997(9):1941-1949

14. Gutmann V (1968) Coordination chemistry in non-aqueous solvents. Springer, Wien

15. Gutmann V (1978) The donor-acceptor approach to molecular interactions. Plenum, New York

16. Kamlet MJ, Taft RW (1976) J Am Chem Soc 98:377-383

17. Kamlet MJ, Taft RW (1976) J Am Chem Soc 98:2886-2894

18. Fowler FW, Katritzky AR, Rutherford RJD (1971) J Chem Soc B 460-469

19. Marcus Y (1993) Chem Soc Rev 22:409-416

20. Katritzky AR, Tamm T, Wang Y, Sild S, Karelson M (1999) J Chem Inf Comput Sci 39:684-691

21. Wrona PK, Krygowski TM, Zielkowska U (1989) Z Naturforsch 44b:673-678

22. Frisch MJ, Trucks GW, Schlegel HB, Scuseria GE, Robb MA, Cheeseman JR, Scalmani G, Barone V, Mennucci B, Petersson 
GA et al (2009) Gaussian 09 (revision A.02). Gaussian, Inc., Wallingford

23. Becke AD (1988) Phys Rev A 38:3098-3100

24. Lee C, Young W, Parr RG (1988) Phys Rev B 37:785-789

25. Mayeux C, Burk P, Gal JF, Kaljurand I, Koppel I, Leito I, Sikk L (2014) J Am Soc Mass Spectrom 25:1962-1973

26. Burk P, Koppel IA, Koppel I, Kurg R, Gal JF, Maria PC, Herreros M, Notario R, Abboud JLM, Anvia F, Taft RW (2000) J Phys Chem A 104:2824-2833

27. Rodgers MT, Armentrout PB (2007) Int J Mass Spectrom 267:167-182

28. Woodin RL, Beauchamp JL (1978) J Am Chem Soc 100:501-508

29. Laurence C, Gal JF (2010) Lewis basicity and affinity scales: data and measurement, ch. 6. Wiley, Chichester

30. Boys SF, Bernardi F (1970) Mol Phys 19:553-566

31. Keith TA (2010) AIMAll version 10.05.04 (http://aim.tkgristmill. $\mathrm{com} /$ )

32. Szatylowicz H, Krygowski TM, Palusiak M (2012) Struct Chem 23:1711-1721

33. Pearson RG (1963) J Am Chem Soc 85:3533-3539

34. Parr RG, Pearson RG (1983) J Am Chem Soc 105:7512-7516
35. Espinosa E, Alkorta I, Elguero J, Molins E (2002) J Chem Phys 117:5529-5542

36. Raczyńska ED, Hallman M, Kolczyńska K, Stępniewski TM (2010) Symmetry 2:1485-1509

37. Born M (1920) Z Phys 1(1):45-48

38. Pauling LC (1960) The nature of the chemical bond, 3rd edn. Cornell University Press, Ithaca

39. Marcus Y, Kamlet MJ, Taft WR (1988) J Phys Chem 92:3613-3622

40. Marcus Y (1985) Ion solvation. Wiley-Interscience, Chichester, (a) pp 107-108, (b) pp 133-135, (c) pp 41-43

41. Fawcett WR (2004) Liquids, solutions, and interfaces. From classical macroscopic descriptions to modern microscopic details. Oxford University Press, Oxford, (a) p 105, (b) pp 97-111, (c) p 109, (d) pp 106-111

42. Blum L, Fawcett WR (1992) J Phys Chem 96:408-414

43. Fawcett WR (1999) J Phys Chem B 103:1181-1185

44. Jaworski JS (2014) J Electroanal Chem 729:75-79

45. Krygowski TM, Radomski JP, Rzeszowiak A, Wrona PK, Reichardt C (1981) Tetrahedron 37:119-125

46. Buckingham AD (1957) Disc Faraday Soc 24:151-157 